\title{
AC 2007-2553: RAPID PROTOTYPING TECHNOLOGY'S NICHE IN DEVELOPING PRODUCT INNOVATION AND COMMERCIALIZATION CENTERS
}

\section{David Street, Rochester Institute of Technology}

received BS degree in Mechanical Engineering Technology (MET) from Rochester Institute of Technology. He is graduate student at RIT in the Manufacturing and Mechanical Systems Integration department. His research interest includes rapid prototyping, product innovation \& commercialization, and rapid product development.

\section{jack danziger, Rochester Institute of Technology}

is currently working on receiving a BS degree in MET and a MS degree in professional studies with concentrations in industrial design and product development. He has attended the Danish Design School in Copenhagen, Denmark studying Scandinavian Furniture Design where he designed and constructed prototype furniture. He is currently focused on developing techniques for using rapid prototyped parts to create short run molds for use in composite construction. His research interest include rapid manufacturing, rapid prototyping, product innovation and commercialization, and rapid product development

\section{William Leonard, Rochester Institute of Technology}

is the program chair has been on faculty in the MET Department at Rochester Institute of Technology since 1998. Bill has a BSME from the College of Engineering at RIT and an M.S. at RIT. He has specialized in the rapid prototyping of products using physical modeling systems such as CNC, rubber molding, and 3D printing machines such as Fused Deposition Modeling, Selective Laser Sintering, and wax based lay up systems. His research interests include rapid product development with a focus on innovation and commercialization. 


\section{Rapid Prototyping Technology's Niche in Developing a Center for Product Innovation and Commercialization}

abstract

The days of build-test-fix appear to be coming to a close. The key to this change is manufacturing through rapid prototyping (RP), a new process that is facilitating more efficient product development. RP is becoming a manufacturing tool that is also being utilized by the university and students to support innovation and entrepreneurship amongst the academic and business community. Some of RP's strength's are in its versatility and ability to prove a concept. Often used by manufacturing representatives, RP provides fast response to marketing and an equally fast production turnaround. RIT recognizes the strengths that RP can provide and is making an effort to institute RP in a new non-profit Center for Product Innovation and Commercialization (CPIC). This entrepreneurial based center provides an avenue for students looking to expand their experiential learning base. The new center will allow individuals from cross-disciplines to connect and hone products through the means of rapid manufacturing. A focus on fast response to marketing, Proof-of-Concept, and market testing will be seen from a faculty, student, and business perspective. The procedure and quality control issues associated in creating this new center, as well as an exploration into continual improvement will be developed. Data will be provided that supports an increasing interest in learning by students as a result of allowing them to develop their own ideas and interests.

introduction

With the new era of technology and present pace of industry, RP presents itself as a viable entrepreneurial and learning tool. These RP machines aid in the students' experiential learning and assists them in joint academic/business ventures. Many advancements have taken place that allow for more flexibility in the machine's uses. With more then twenty years use, RP machines are starting to become more affordable to smaller businesses and individuals. This allows colleges with minimal financial flexibility to purchase and capitalize on this equipment.

RP's power rests in the machines ability to take a concept and quickly turn it into a physical model to be displayed and analyzed. These RP machines are a powerful tool for those who wish to impose quality standards like Six Sigma or Total Quality Management (TQM). Quality is accomplished by front-loading the design process. This entails making and refining most of the design errors before capital is invested in manufacturing. The new process allows for a shorter iterative cycle as compared to the old build-test-fix model. Figure 1 is an evaluation of the design cycle (Ullman, p 180) ${ }^{1}$. 


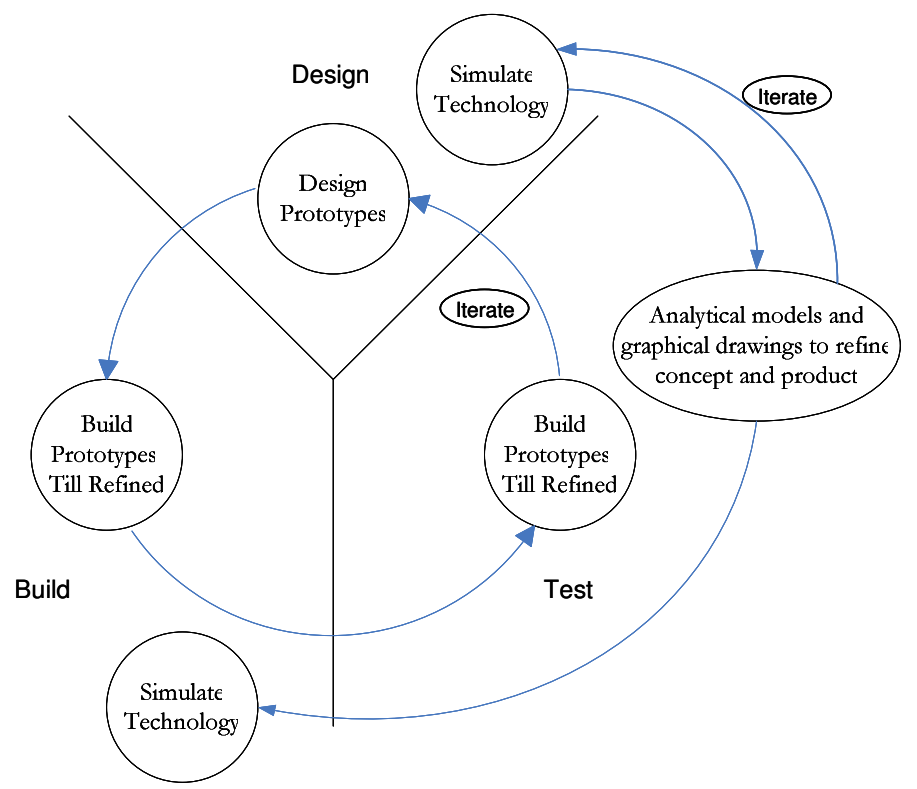

Figure 1 Design evaluation cycle

Knowing the strategic advantages of RP machines and seeing industrial growth, RIT's Mechanical Engineering Technology (MET) department has decided to purchase a variety of different machines.

One machine purchased is the Z-Corporation Spectrum Z510 machine. This is a 3-dimensional color printer that sprays binder on a gypsum based powder. From an entrepreneurial stand point it has versatility. It is able to produce molds for both nylon and cast aluminum parts. This nearly eliminates the need for tooling costs to develop prototypes. Another aspect of its versatility comes in the planning for deliverables.

The RP machines have four strengths ("The Four P's"). They are Proof-of-Concept, Proof-ofProduct, Proof-of-Process, and Proof-of-Production (Ullman p 97) ${ }^{1}$. All of which combine to develop a product that is robust enough to withstand a certain degree of noise in the engineering process. RP machines have more versatility today then ever before with their ability to create fully functional parts that can be tested immediately.

Each year more companies are opting to purchase RP machines and develop their products through an assortment of different types of physical modeling. According to a January 17, 2005 press release by Z-Corp. a move was made to an 80 percent larger facility with 25 percent more employees. In 2005 the RP industry was projected to have sales around 655 million with roughly five million models being produced (Rowe, 2004) ${ }^{2}$. RIT's MET department has seen an increase in enrollment in product realization courses that offer the chance to develop product with these new machines.

discussion and analysis

There are a number of other universities that utilize the RP process. Some of these universities include University of Texas at Austin (UT), Georgia Tech, MIT, and Louisville. The focus is 
faculty driven research with student support. At the CPIC at RIT, the focus is reversed. Its distinction is a student-industry partnership that will together define projects for research. Faculty become a guide and mentor. This will be of a more applied nature that looks to bring viable thoughts and ideas straight to market.

This is where the CPIC gives students support. The center will provide the necessary machines to develop each entrepreneurial student's prototypes. The equipment will consist of table top drill presses, small grinders and a series of different prototype machines. Two of the machines currently in house are Z-Corp.'s Spectrum Z510 (discussed earlier) and an earlier model (Z402) which uses starch based powder. Two other machines currently in house are the Dimension BST (an RP machine that prints $\mathrm{ABS} \circledast$ plastic) and a wax modeler that allows for lost foam method. These are some tools and best practices that entrepreneurs can use to develop future products.

The current means to develop sound product innovation and entrepreneurial practices are found in RIT's MET department, consisting of a set of three classes: Product Idea and Concept Selection, Develop-Design New Products, and Product Realization. To start the product realization course series, future entrepreneurs need to have at least three years experience in engineering or a related field. The first course deals with formulating and documenting ideas as well as developing the voice of the customer (VOC) and any issues that may arise with patenting. Once that information is gathered, students then learn how to use a house of quality matrix to develop and rank product requirements so that Pugh selection matrix can be utilized. The second course in the series takes the information developed in the first class and asks students to develop their ideas further. Here the students will delve into feasibility studies, develop product specifications from the VOC, and define a preliminary manufacturing and assembly feasibility assessment. CAD will be the "tool of choice" where all work will be documented and handled with a standard release procedure that parallels industrial protocol. It is expected that this product phase will require the implementation of fundamental principles learned from the first course. The third course in the series takes all previous work and applies it to creating working models. Students will be designing, manufacturing, and assembling the product in a way that aligns with their value analysis and process control, all the while being responsible for setting up test procedures and evaluating the product.

These three courses are meant to give future entrepreneurs hands on experiential learning. Industry has long requested that students have more hands on experience. Here the students can develop ideas from the ground up along side industrial partners if applicable. The CPIC is not Engineer-specific, the center is meant to bring students from multiple disciplines together to work towards a common goal. The CPIC presents industrial experience in a safe, cost effective manner. Most students upon graduation will eventually work with industrial designers/engineers, marketing, and other disciplines. This center replicates a common trend in business to have cross-functional teams working on a project together. In so doing students will also face common challenges such as communication, bureaucracy, and other hurdles that effect projects routinely.

The CPIC will also provide students an option to participate in an industrial outreach program, from which students can research and develop products for industry. It also provides students a chance to network, not only with industry but with other students that are participating in research. Having students involved in the process allows companies to allocate resources to other 
crucial areas of product development, which in turn provides gains in turnaround time for product placement. This practice keeps the company's product development costs to a minimum. The center is non-profit and only asks that material cost be covered.

The CPIC uses RP as a means to market test. The purpose is to evaluate the viability of a nonprofit enterprise operating out of an academic institution. The center's goal is to answer the basic questions every business seeks to answer, "Do people have interest? Do people want the service?" It is not in the center's interest to compete with industry providing the same service. It is, however, one of few facilities that offer RP machines for use. The center spent a year in a phase known as "loss leader" providing services for free. This offered the center a means of market testing that gained interest, not only academically but industrially as well.

It is within the scope of the CPIC to provide products on time and within the scheduled budget. Rapid manufacturing and RP's shorter iterative cycle provides industry with a fast response to market. In this global economy this is imperative, and from a student perspective this can be very challenging. Since many students will have had minimal industrial experience it is the responsibility for the sponsoring faculty member to provide students with support. Support can range from helping on clerical errors to the theory involved in developing a new product. This ensures that the students won't feel so overwhelmed that they have withdrawal or abandonment issues.

This is where RP plays a crucial role. It provides students and faculty better means to communicate with each other and industry by creating physical models. Students acquire a means of proving "The Four P's". Errors that might not be noticed in a CAD file can now easily be seen and corrected.

In the past, approximately a group a month would visit the center to produce models for their business. The center is now seeing three to four groups a week. The CPIC is now overrun with requests to gain access to the courses and equipment. One of the center's biggest customers is the Mechanical Engineering Department. The center found that ME's senior design teams used the RP machines more then any other customer. As well, industrial design is on board and usually uses these machines as Proof-of-Concept. Other customers come from industry and include companies like GM Fuel Cell, Delphi, and Johnson \& Johnson. Entrepreneurial students are provided vast opportunities to work with other academic departments, industry, and individual entrepreneurs.

An example of what can be produced at the center came from the industrial design program. Students developed pieces for a board game to be manufactured in conjunction with an industrial partner. The pieces consist of an elephant and donkey (Figure 2). Another adventure that is being explored by RIT is facial scanning. Individuals can have exact replicas of their face printed (Figure 3). Color can be applied during the print cycle by marrying a JPEG to the STL file. The versatility this facility provides entrepreneurial students can also be seen in a fully functional miter saw guide produced by Project Lead the Way students (Figure 4). 


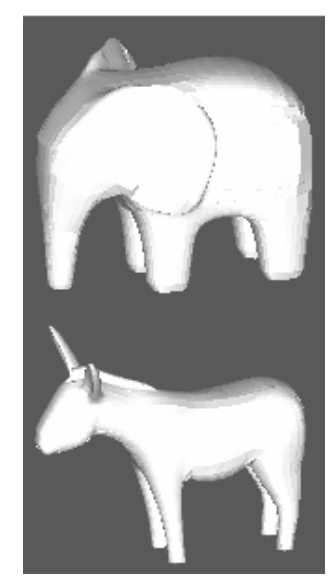

Figure 2 Screen shot of game pieces

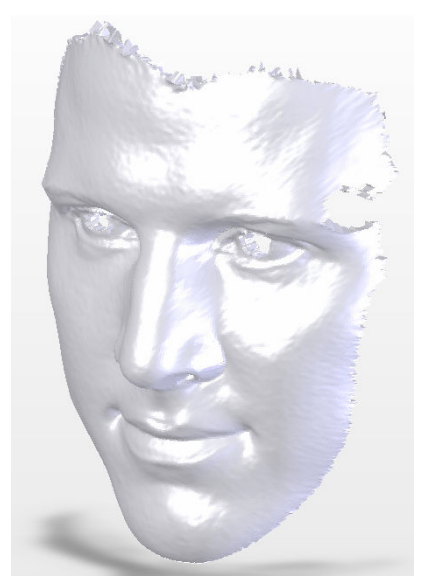

Figure 3 Plain STL facial scan

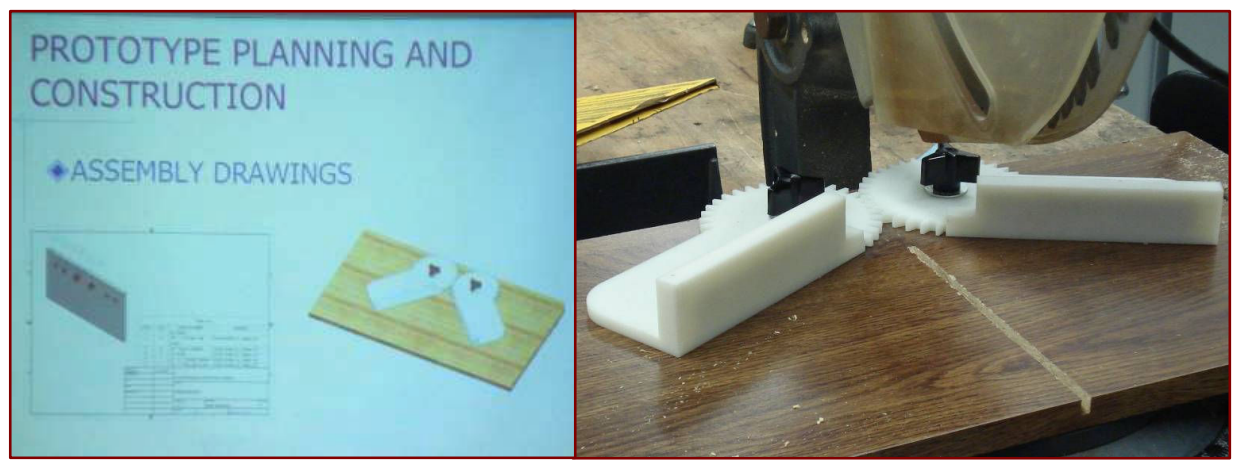

Figure 4 PLTW miter saw

Industry often comes to the CPIC for use of the RP machines to prove "The First P". Wilson Manifolds is one example. A valley tray was produced to satisfy Proof-of-Concept and Proof-ofProduct. The use of the RP machines permitted Wilson Manifolds to evaluate the product's primary concerns. Most industries that use this service enjoy fast response time. Market testing can be done within a matter of days. If refinements are needed, updating the STL file is all that is required. Simulation has been proven useful for answering "The Four P's" but is not a substitute for having a 3D model in hand.

The advantage of using specialized equipment in student research is an experiential learning base. Not only do students get hands on experience but also RP provides the students better means to communicate complex thoughts and theories. The basis of this center allows students means to network with peers, faculty, and industry located in the area. Students remaining on campus can further their course work at a more rapid pace than students opting for an offsite coop learning experience. With the aid of the equipment and support of faculty/industry, patent opportunities are a strong possibility. The speed of the machines is therefore vital. Average turnaround time on RP machines is roughly 48 hours. Another advantage would be participation in the product realization course series. CPIC enrollment is on the rise and the center is gaining interest from other disciplines such as industrial/graphic design, and business to name a few. 
There are drawbacks to using RP machines. One issue is feature creep, the addition of functions or features that were neither originally intended for the product nor specified on the product requirement document. Another problem is the limitations of the machines. The Z-Corp. Z510 can print complex parts but sacrifices part strength and dimensional accuracy. Secondary operations may be required to enhance durability. Knowing the application of the RP parts will aid in determining if secondary operations will be needed. The Dimension BST has greater durability but takes longer to produce a part. Once printed, however, there is no need for secondary operations.

Although these limitations exist, the center is able to supply a degree of quality assurance. Experimentation has shown that parts produced on the Spectrum Z510 tend to swell. An investigation including statistical process control was conducted. This determined the average swell to be 0.01 inch/inch. When the print heads reached approximately a liter of binder spray a dramatic degradation effect was found to occur in part quality. This can be seen in Figure 5. Once the binder limit was reached, dimensional accuracy failed to reach the upper tolerance limit (UTL).

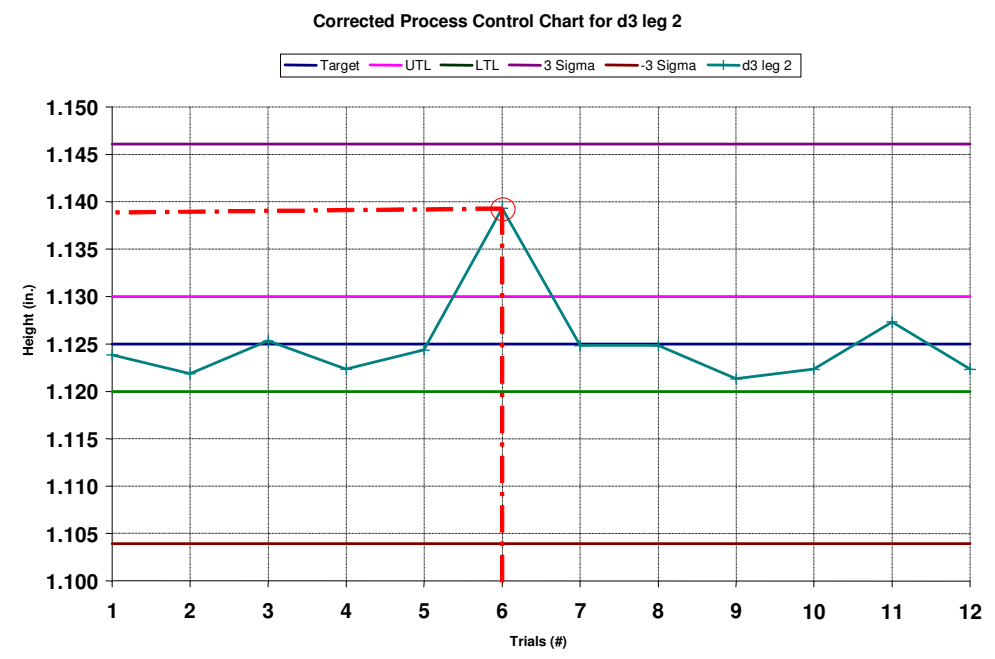

Figure 5 Display of Machines Physical Limit

Further details on this investigation can be found in "Creating Rapid Prototyped Enterprise Quality Molds that can Produce Fully Functional, Testable Parts." (D. Street, et.al. ASEE Cornell 2006) ${ }^{3}$

Machine performance is not the only matter that needs to be addressed. A continual improvement program must also be setup so the CPIC can remain competitive in the future. One means to achieve this is to tie into a national RP center that has the resources to advance new and emerging technology. The Saddleback Community college is one such facility. Located on the west coast, it is another academic program.

Other means for continual improvement will be the students themselves. One theory is to provide cooperative education credit to students interested in participating in research that would refine 
process control, work flow, and other meaningful initiatives. In this environment students will be expected to report their findings to advisors and possibly present work for publication at a regional or national conference.

One example of continuous improvement project was to perform a Taguchi analysis of the Z510 machine. Here an $\mathrm{L}^{9}$ array was used to evaluate the level setting of the machine. Table 1 displays the control factors and level setting used to analyze the Z510 for its most optimal performance.

Table 1 Factor and Level Settings

\begin{tabular}{cc|ccc}
\hline & Control & \multicolumn{3}{|c}{ L9 Array } \\
Factors & \multicolumn{3}{c}{} \\
\hline \hline & Factor & Level & Level & Level \\
& I & II & III \\
A & Rot- x & $0^{\circ}$ & $45^{\circ}$ & $90^{\circ}$ \\
B & Rot- y & $0^{\circ}$ & $45^{\circ}$ & $90^{\circ}$ \\
C & Position & Left & Center & Right \\
D & Depth & Low & Medium & High
\end{tabular}

The purpose of this analysis was to determine the best possible build orientation that can be accommodated by the machine. This report slated for 2007 develops the standard operating procedure to be followed so student researchers can focus on the task at hand without unnecessary distractions.

conclusion

With RP machines becoming more affordable the technology is increasing in viability for academic and individual use. Its primary function is proving "The Four P's". Given that RP can quickly take a concept and turn it into a physical model, this technology can spur intellectual growth through hands on participation. The CPIC encourages students from multiple disciplines to collaborate and work towards a common goal, while facing normal industrial challenges. This program's distinction from other universities offerings is that the student-industry partnership will define the project of research while faculty is there for support. Support from the professors will consist of helping with clerical errors to the theory in involved in developing new products and being on guard for feature creep. Given the nature of this facility a continual improvement program will be rigorously explored and improved upon throughout the life of this center. Thus providing every participant a quality means of education.

acknowledgements

Special thanks to Leslie L. Gregg for all her efforts and cooperation 
bibliography

[1] Ullman, G., David, (2003). The Mechanical Design (3rd ed.). New York: McGraw-Hill.

[2] Rowe, Jeff. (May 10, 2004). MCAD Product Review Update. MCAD Weekly. 12-20-06. http://www.mcadcafe.com/

[3] Street, David, et al (Nov. 2006). "Creating Rapid Prototyped Enterprise Quality Molds that can Produce Fully Functional, Testable Parts.” ASEE St. Lawrence Section Proceedings. 